\title{
Effect of Dust Accumulation and Cleaning Process on Solar Reflectivity of some Building Materials
}

\author{
Amre Deif
}

\begin{abstract}
In countries that are suffering from hot weather, a considerable part of energy is dedicated for cooling the buildings due to the absorbed part of the incident short-wave which results in an increase of the surface temperature of the roof. To overcome this problem, a bright (white) surface can be used to reflect the solar radiation. On the other hand, the Photovoltaic (PV) panels are widely used to convert the sun light into electricity. However, the dust accumulation either on the reflective materials or on the PV panels will cause a substantial reduction on their performance. The present work is a dualutility because it studies both the effect of dust deposition on the reflectivity of some surfaces and as well the effect of the cleaning process.
\end{abstract}

Keywords-dust, accumelation, reflectivity, cleaning process, $P V$, energy savings.

\section{Introduction}

Dust accumulation that reduces the reflectivity and surfaces transmittance is mainly depends on rain, humidity, temperature, wind speed, surface inclination, height of the surface and cleaning process. The proper cleaning technique in the proper time should be optimised in order to achieve the optimum performance of either reflective materials or the transmittance of the surfaces.

Roth and R.B. Pettit [1], conducted an outdoor experiment on three sets of mirrors fixed at five different angles: $0^{\circ}, 30^{\circ}$, $45^{\circ}, 60^{\circ}$ and $180^{\circ}$ "inverted" and were periodically cleaned at 2, 6 and 12 days. They reported that the environmental conditions can quickly decrease the efficiency of the reflective materials due to the exposure to the dust by 0.006 reflectance units daily. They also mentioned that the geography can cause more reflectivity loss due to other pollutants.

Guan et al. [2] examined a metallic test bench that has various solar mirrors. They found that the drop in the reflectivity of the mirrors due to the dust accumulation was $72 \%$ in one month in case there is no rain. They mentioned that the nature of the surface, relative humidity, rainfall, wind and temperature are factors that affect the dust deposition. Similar concepts were obtained by Al-Helal IM. and Alhamdan AM. [13] in which the reduction of solar radiation dropped by $9 \%$ within 30 days and dropped by $5 \%$ after elapsing 11 months.

An interesting study done by Hamdy K. Elminir et al. [3]

Amre Deif

Civil Engineering Department

Jubail University College

Royal Commission for Jubail and Yanbu

Kingdom of Saudi Arabia in which 100 glass samples of size $10 \mathrm{~cm}$ x $10 \mathrm{~cm}$ were placed at $0^{\circ}, 15^{\circ}, 30^{\circ}, 45^{\circ}, 60^{\circ}, 75^{\circ}$ and $90^{\circ}$ and tested against dust accumulation. Their findings showed that the transmittance was mainly affected by the density of the dust along with the tilting angles. They got some "erratic" results; probably one of the reasons is that they did not consider the aerodynamic effects of the nature of their experimental setup.

Dietz A. [14], used glass panels of different tilting angles ranges from $0^{\circ}$ to $50^{\circ}$ to see the effect of dust accumulation; he reported that the solar radiation was reduced by $5 \%$; Meanwhile, the transmittance dropped in a range between $64 \%$ and $17 \%$ for tilting angles $0^{\circ}, 15^{\circ}, 30^{\circ}, 45^{\circ}$ and $60^{\circ}$ in the study conducted by Ghazi S, and Sayigh A Ip K. [18] in which the samples were exposed to dust for 38 days.

Mani and Pillai [4], conducted an experiment that entirely used artificial dusts such as limestone, cement and carbon particulates under constant halogen lamps. They reported that the finest particulates had the most deteriorating effect on the $\mathrm{PV}$ efficiency as compared to the coarser one and the dust accumulation is higher in case of horizontal surfaces. They found that strong wind can cause cleaning to the surfaces and the roughness of the surface can affect the amount of dust deposition.

The effect of the types of surfaces as well as the particle size was also reported by Cabanillas, R.E. and Munguia, H. [15], after their test that lasted for 3 months, they found that the power was dropped to a range of $4-7 \%$ in case of crystalline Si modules whereas the range of the drop was 8 $13 \%$ in case of amorphous Si modules.

In a solar-village next to Riyadh that was exposed for eight months, Salim A. et al. [5], found that the dust caused a reduction in the performance of the system by 32\%; where the reduction was $2.4 \%$ per year due to the dust storm conditions in the study conducted by Bethea RM. Et al. [10].

A lab work was performed by EI-Shobokshy MS. and Hussein FM. [6] in which neither wind nor natural desert dust were used; they found that the efficiency of the PV was affected by the material of the dust and as well as by its size. A theoretical study by Cuddihy EF. and Willis PB. [11] showed similar concepts in which the dust deposition depends on the "dust morphology/size data."

In the study conducted by Mastekbayeva GA. and Kumar S., [7], the transmittance was reduced by $11 \%$ due to the effect of dust for one-month exposure in humid environment where as Katz GB. [8] reported that a $2 \%$ reduction in the generated current compared to the cleaned panels. While the drop in transmittance for the polyethylene glazing was ranging from 
$87.9 \%$ to $75.8 \%$ within 30 days of exposure in high humidity environment (Mastekbayeva and Kumar [16]).

Due to the clustering of dust particles, Neil S. et al. [9], described numerical and analytical models in a dry area. The trend of the models looked like an exponential decay.

The effect of dust accumulation on the electrical current in indoor and outdoor conditions was studied by Abhishek R. et al. [12]. They found that the indoor current in short circuit was sensitive to the dust approximately 8 times compared to that of the outdoor setup.

This paper presents some of the results of an experimental program in which 16 different samples were exposed to dust for different periods of time. The reflectivity is measured at four different steps: right at the end of each period (virgin), after blowing the dust, after washing by tap water and after using domestic detergent of $1 \%$ concentration. The objective of this research is to investigate the effect of dust accumulation on different surfaces and the resulted reflectivity along with the cleaning mechanism. In order to measure the short-wave solar reflectivity, 410-Solar / NIR Hand-Held Reflectometer was used.

\section{Experimental Program}

\section{A. Test Specimens}

Four groups of samples were used: the first group is a white Plexiglas exposed to 10 day of weather exposure, the second group is also Plexiglas subjected to three weeks of weather exposure, the third group is one of the commercial reflective paint and was exposed to only 10 days of weather exposure as it was received quite late, and the fourth group is the conventional bituminous membrane.

The summary of the test samples is shown in Table 1 . It is important to mention that every group is composed of four samples of dimensions $300 \mathrm{~mm}$ x $300 \mathrm{~mm}$. The reason to have four panels is to deeply study the trend of the obtained data and after that the average was taken; as shown in Fig.1.

TABLE I. THE TEST SAMPLES

\begin{tabular}{|c|l|c|}
\hline \multirow{2}{*}{ Group } & \multicolumn{1}{|c|}{ Description } & Time to weather \\
exposure (Days)
\end{tabular}

The test specimens were placed on the roof of the test facility that was recently built at the campus of Jubail University College (JUC), the hieght of the facility is $3.57 \mathrm{~m}$. A weather staion was installed on the roof of the test facility at the height of $3 \mathrm{~m}$ above the roof and with a total height of 6.57 $\mathrm{m}$ above the ground level. The weather staion consists of the following components: Anemometer; Wind direction indicator; Rain gauge; Humidity meter; and Temperature thermometer. All weather data can be obtained every 5 minutes; the test facility and the weather staion are shown in Fig. 1 and Fig. 2 respectively.

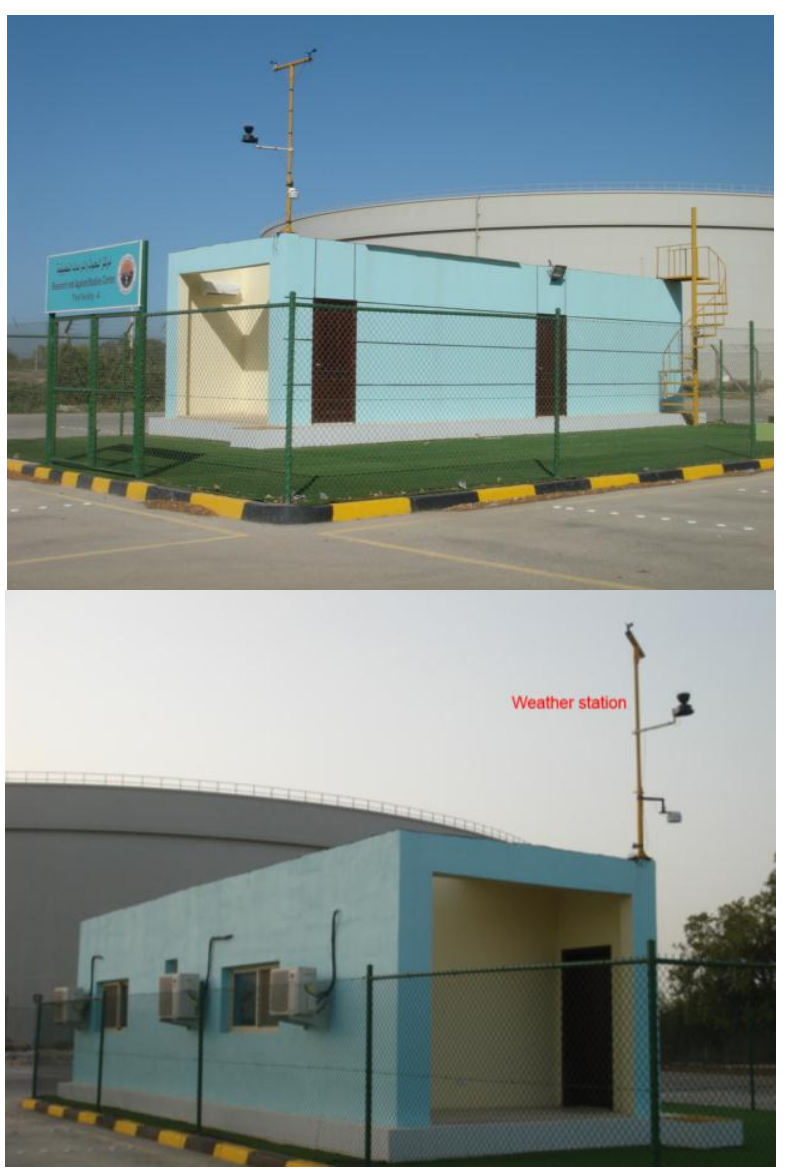

Figure 1. Test facility at JUC.

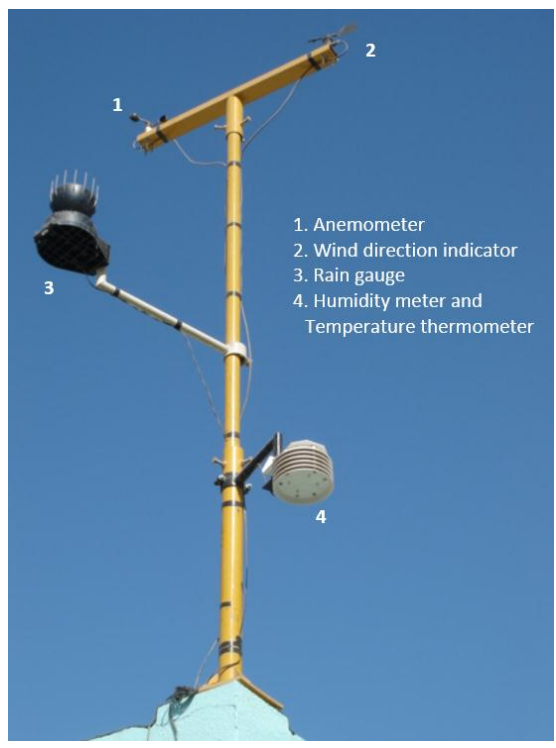


Proc. of the Seventh Intl. Conf. on Advances in Civil, Structural and Mechanical Engineering - CSM 2018 Copyright (C) Institute of Research Engineers and Doctors, USA .All rights reserved.

ISBN: 978-1-63248-163-4 DOI: 10.15224/978-1-63248-163-4-22

Figure 2. Weather station.

The painting of the commercial reflective material was conducted in two layers' perpendicular to each other (Fig. 3) to assure that the whole area is covered by the paint and the time between the two is not more than a day. Arrangement of each group of samples is shown in Fig. 4.

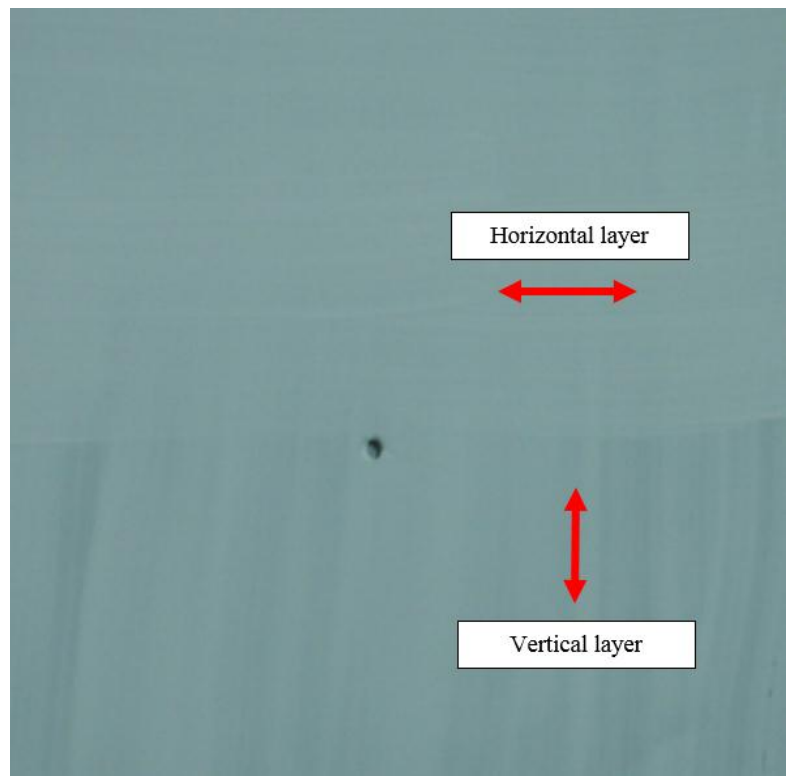

Figure 3. Painting process of the commercial reflective material.

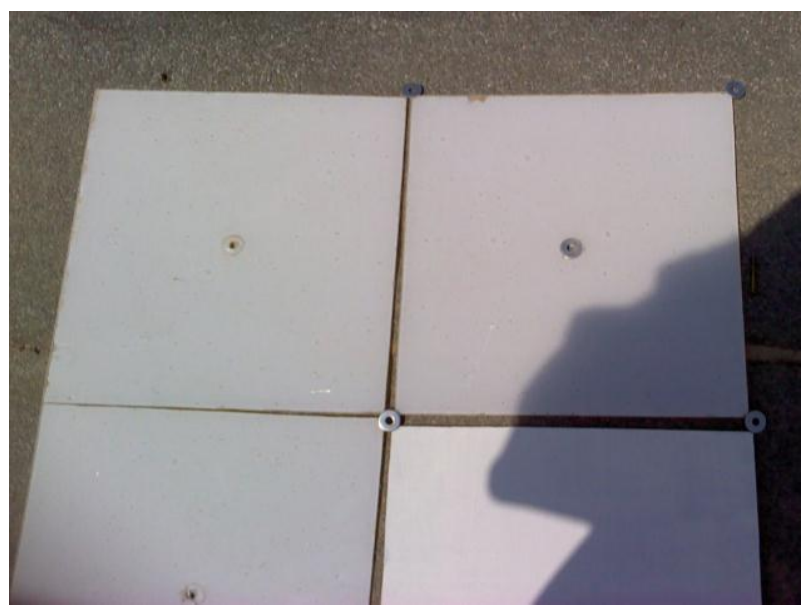

Figure 4. Arrangement of each group of specimen.

\section{B. Measuring reflectivity}

The reflectivity was measured by means of 410-Solar Reflectometer, shown in Fig. 5. The reflectivity measurements were taken at four different stages:

i. At the time of taking the samples from exposure condition (virgin);

ii. After blowing (to simulate the wind) with air blower of 550 Watts, $2.7 \mathrm{~m}^{3} / \mathrm{min}$; shown in Fig.6; iii. After washing with tap water (to simulate the rain); and

iv. After cleaning with commercial domestic detergent.

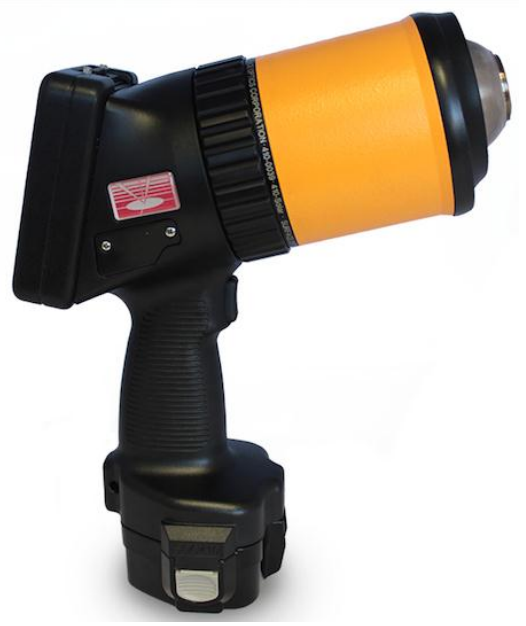

Figure 5. 410-Solar Reflectometer.

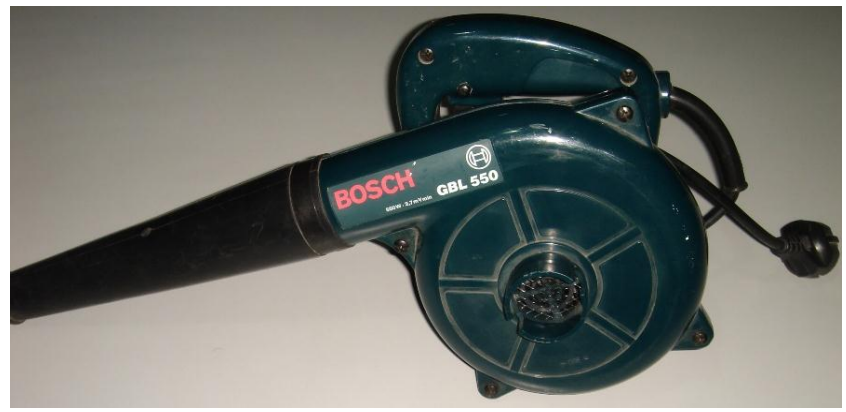

Figure 6. The blower used to clean the dust.

The washing by tap water was conducted by using a bottle with a nozzle to simulate the rains, whereas, a commercial domestic detergent of $1 \%$ concentration was used to clean up the dust by a brush, Fig. 7, and after that was rinsed by tap water, Fig. 8.

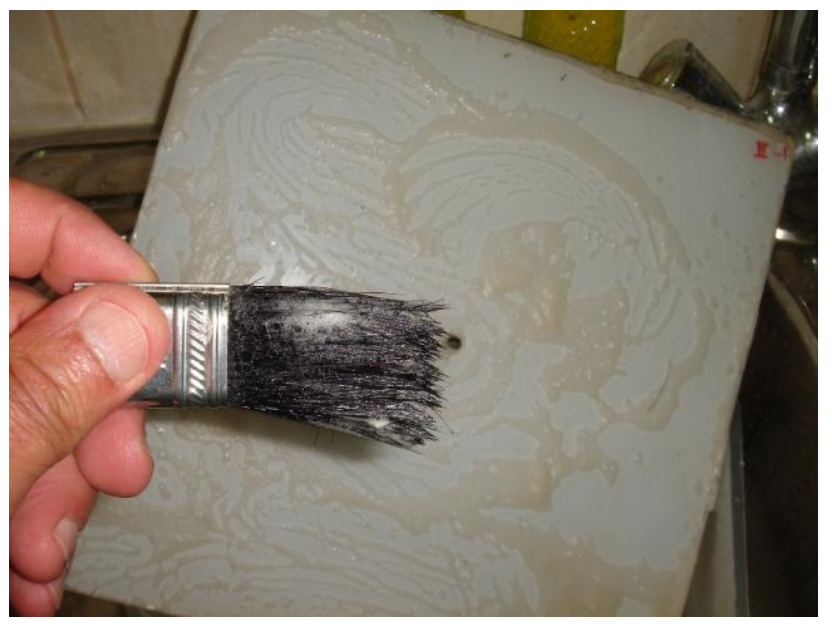

Figure 7. Cleaning process by using a commercial domestic. 
Proc. of the Seventh Intl. Conf. on Advances in Civil, Structural and Mechanical Engineering - CSM 2018 Copyright $(\odot$ Institute of Research Engineers and Doctors, USA .All rights reserved.

ISBN: 978-1-63248-163-4 DOI: 10.15224/978-1-63248-163-4-22

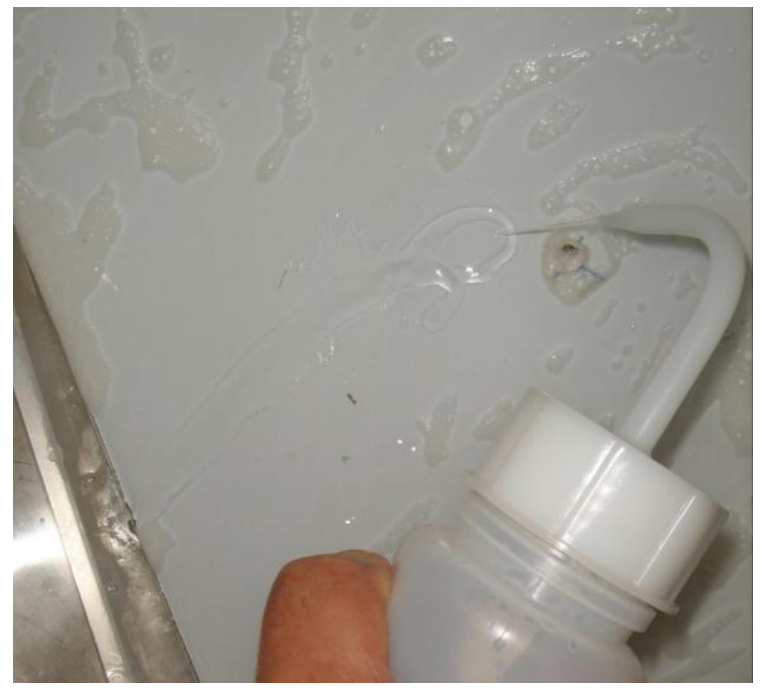

Figure 8. Rinsing the detergent.

The cleaning of the bituminous membrane was done in the same way of the cleaning of the Plexiglas samples and was rinsed with plenty of water, Fig. 9.

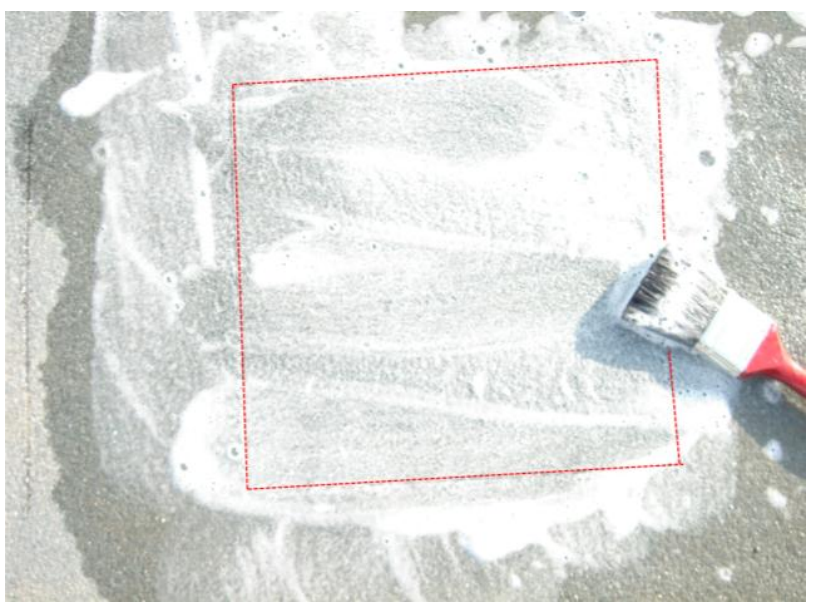

Figure 9. Cleaning of the bituminous membrane.

\section{Test Results and Discussion}

The obtained measurements for group I, Group II, reflective paint and conventional bituminous membrane are shown in Fig. 10 to Fig. 13 respectively.

From the obtained results, all materials except the conventional bituminous membrane almost have the same trend. It is clear that the dust affects negatively on the reflectivity of the surfaces; it is also clear that the blowing process increases the reflectivity. The best reflectivity can be obtained by just using water. The unexpected phenomenon which is almost common in all the obtained results is that using the detergent affects negatively the reflectivity. This could be attributed to the damage that could happen on the top surface of the samples.

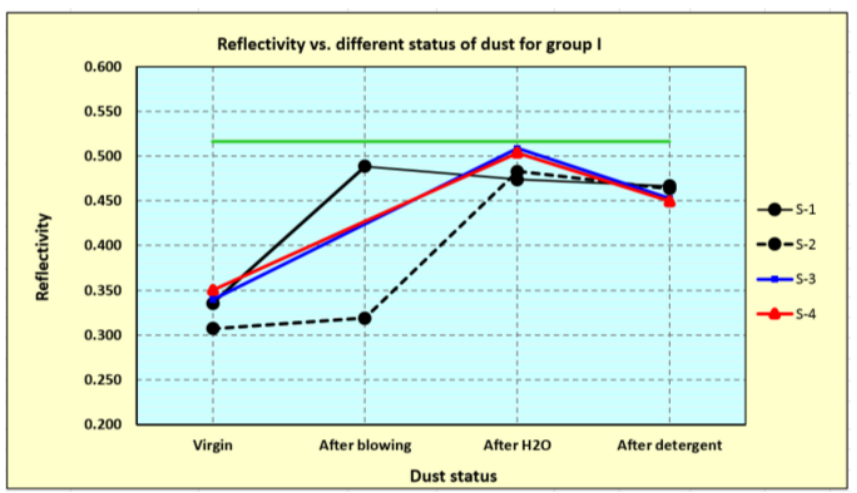

Figure 10. Reflectivity vs. different stages of dust for group I of samples.

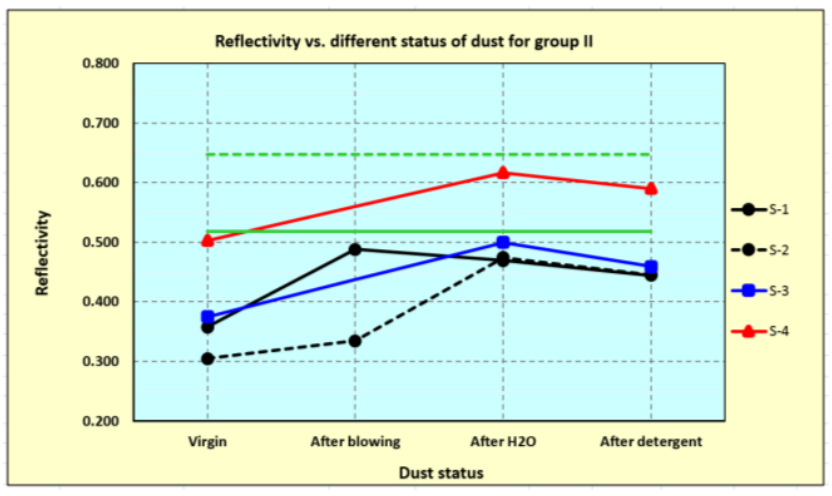

Figure 11. Reflectivity vs. different stages of dust for group II of samples.

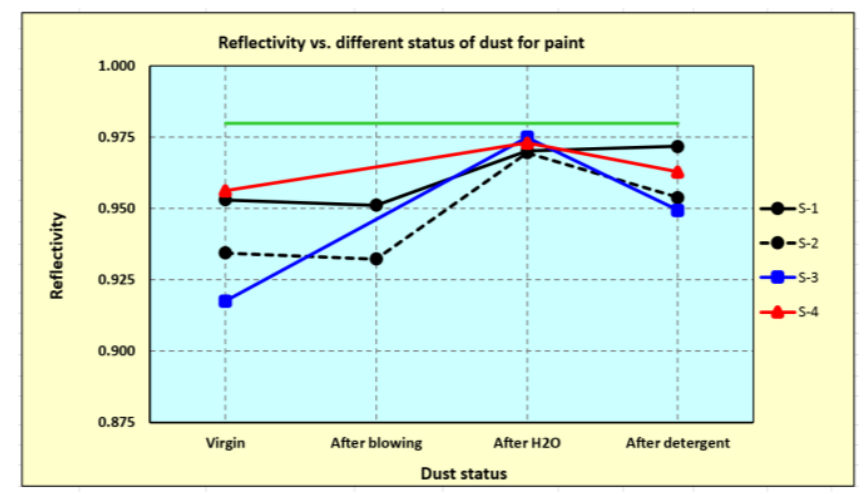

Figure 12. Reflectivity vs. different stages of dust for painted samples. 


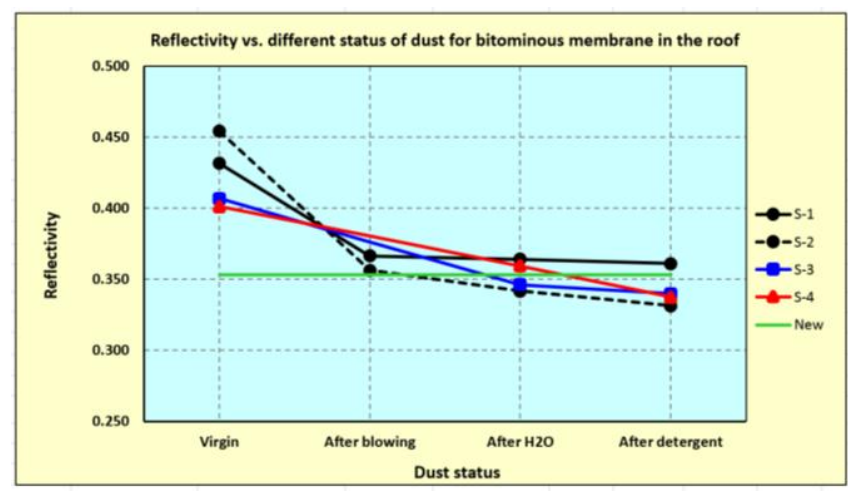

Figure 13. Reflectivity vs. different stages of dust for bituminous roof.

Although the time of exposure of group II (Plexiglas of white surface) was longer than that of group I (same material), but at virgin condition for both, they have almost the same reflectivity. This can be interpreted by wind blowing during this time causing the removal of some dust and consequently increases the reflectivity.

Another interesting result can be seen in Fig. 14 which is related to the the reflectivity of the bituminous membrane versus different conditions of cleaning. The data can be divided into three distinct zones; the first zone at the left (the vertical oval shape) in which the dust increases the reflectivity of the bituminous membrane drastically by almost 0.1 which can be considered a big value. In the second zone (the horizontal oval shape at the middle), the reflectivity decreases by using the blowing and water as the dust is removed from the surface. Finally, in the third zone, again, using the detergent decreases the reflectivity.

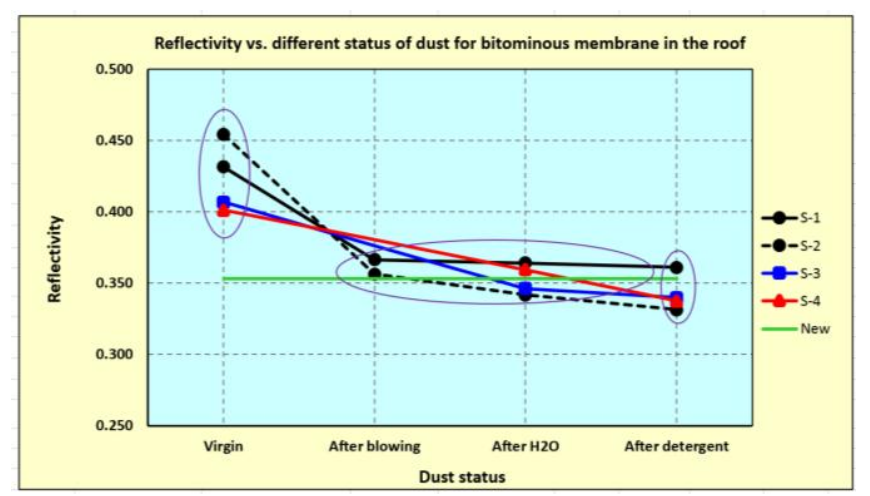

Figure 14. Effect of dust on the bituminous membrane.

\section{Iv. Conclusions}

This research was conducted to study the effect of dust accumulation on the reflectivity of three different materials: Plexiglas of white surface, commercial reflective paint and conventional bituminous membrane. The results revealed that the dust reduced the reflectivity of the surfaces of the first two materials while the dust increases the reflectivity of the conventional bituminous membrane.

The best way to recover almost the reflectivity is to use just water to wash the surfaces and take no action in the case of bituminous membrane.

\section{Acknowledgment}

The author would like to thank both: the management of the JUC and Dr. Saleh Al Shehri, the Director of the Research \& Applied Studies Centre at JUC for their permission to use the test facility and to use the most recent equipment to measure the reflectivity. Thanks are also extended to Engineer Abdulajabar Khamees Hamdeen from the Jubail Technical Institute (JTI) for his great help in preparing the samples.

\section{References}

[1] E.P. Roth and R.B. Pettit, "The effect of soiling on solar mirrors and techniques used to maintain high reflectivity". Supported work by the division of solar technology, U.S. department of energy (DOE), under contract DE-AC 04-76-DP 00789, 1980, pp. 49.

[2] Z. Guan, S. Yu, K. Hooman1, H. Gurgenci and J. Barry, "Dust characterisation for solar collector deposition and cleaning in a concentrating solar thermal power plant". Proceedings of International Conference on Heat Exchanger Fouling and Cleaning. Editors: M.R. Malayeri, H. Müller-Steinhagen and A.P. Watkinson. June 07 - 12, 2015, Ireland, pp. 301-307.

[3] Hamdy K. Elminir, Ahmed E. Ghitas, R.H. Hamid, F. El-Hussainy, M.M. Beheary, Khaled M. and Abdel-Moneim, "Effect of dust on the transparent cover of solar collectors". Energy Conversion and Management 47, 2006, 3192-3203.

[4] Mani, M. and Pillai, R., "Impact of dust on solar photovoltaic (PV) performance: research status, challenges and recommendations." Renew. Sustain. Energy Rev. 14 (9), 2010, 3124-3131.

[5] Salim A., Huraib F and Eugenio N, "PV power study of system options and optimization". In: Proceedings of the $8^{\text {th }}$ European PV Solar Energy Conference, Florence, Italy; 1988.

[6] EI-Shobokshy MS. and Hussein FM., "Degradation of photovoltaic cell performance due to dust deposition on to its surface". Renew Energy 1993,3(6/7):585-90.

[7] Mastekbayeva GA. and Kumar S., "Effect of dust on the transmittance of low density polyethylene glazing in a tropical climate". Solar Energy 2000,68(2);135-41

[8] Katz GB., "Effect of dust on Solar panels,"2011.

[9] Neil S, Beattie, Robert S Moir, Charlslee Chacko, Giorgio Buffoni and Simon H Roberts, "Understanding the effect of sand and dust accumulation on photovoltaic modules," Renewable Energy 2012, 48:448-452.

[10] Bethea RM, Collier EG. and Reichert JD. Dust storm simulation for accelerated life testing of solar collector mirrors. Journal of Solar Energy Engineering 1983, 105:329-35.

[11] Cuddihy EF. and Willis PB., "Antisoiling technology: theories of surface soiling and performance of antisoiling surface coatings," Jet propulsion laboratory report DOE/JPL 1012-102, 1980.

[12] Abhishek R, Rohit P, Monto M, and Praveen R, "Influence of dust deposition on photovoltaic panel performance," Energy Procedia 2014;54:690-700.

[13] Al-Helal IM. and Alhamdan AM., "Effect of arid environment on radiative properties of greenhouse polyethylene cover." Solar Energy 2009, 83:790-8. 


\section{Proc. of the Seventh Intl. Conf. on Advances in Civil, Structural and Mechanical Engineering - CSM 2018 Copyright (C) Institute of Research Engineers and Doctors, USA .All rights reserved.}

ISBN: 978-1-63248-163-4 DOI: 10.15224/978-1-63248-163-4-22

[14] Dietz A. GH., "Diathermanous materials and properties of surfaces," Zarem AM, Erway DD, editors. Introduction to the utilization of solar energy. New York: McGraw-Hill; 1963 p. 59-86.

[15] Cabanillas, R.E. and Munguia, H., "Dust accumulation effect on efficiency of Si photovoltaic modules," J. Renew. Sustain. Energy 3 (4), 043114, 2011.

[16] Mastekbayeva GA. and Kumar S., "Effect of dust on the transmittance of low density polyethylene glazing in a tropical climate". Solar Energy 2000, 68(2);35-41.

About Author (s):

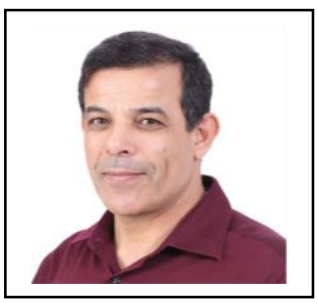

The dust accumulation either on the reflective materials or on the Photovoltaic (PV) panels will cause a substantial reduction on their performance. The present work is a dualutility such as that it studies the effect of dust deposition on the reflectivity of some surfaces and as well the effect of the cleaning process. 